\title{
Endocarditis infecciosa actinomicótica de la válvula mitral. Caso de autopsia y revisión de la literatura
}

\author{
David Oddó B y M. Fernanda Ayala R.
}

Pontificia Universidad Católica de Chile, Santiago, Chile Escuela de Medicina Departamento de Anatomía Patológica (DOB) Estudiante de Medicina (MFAR)

Recibido: 10 marzo 2006 Aceptado: 25 marzo 2007

Correspondencia a: David Oddó Benavides doddo@med.puc.cl

\section{Actinomycotic infective endocarditis of the mitral valve. Anatomoclinical case and review of literature}

Actinomycotic infections of the heart is an uncommon disease, especially if the infection affects the valvular endocardium as primary focus. Just a few cases have been reported previously. We report a case of primary endocarditis of the mitral valve caused by Actinomyces sp diagnosed at necropsy in a 34 year-old man with history of chronic rheumatic disease presenting as a usual case of infective endocarditis.

Key words: Infective endocarditis, actinomycosis, heart infection.

Palabras claves: Endocarditis infecciosa, actinomicosis, infección cardíaca.

\section{Introducción}

$\mathbf{L}$ a endocarditis infecciosa (EI) constituye una enfermedad frecuente, cuya patogenia y agentes causales son bien conocidos. Sin embargo, hay pocos casos descritos en los que los agentes involucrados corresponden a microorganismos del género Actinomyces, especialmente cuando el compromiso endocárdico es primario ${ }^{1-4}$.

\section{Caso anátomo-clínico}

Hombre de 34 años de edad, con antecedentes de enfermedad reumática desde los 6 años, recibió profilaxis con penicilina benzatina hasta los 18 años. Cinco meses antes de su deceso presentó un primer episodio de EI por Streptococcus $\beta$ hemolítico del grupo D, no Enterococcus, y con buena respuesta clínica aparente al tratamiento médico. Reingresó al hospital por un cuadro de insuficiencia cardíaca con falla orgánica múltiple; evolucionó grave, con claro compromiso de las funciones hepática y renal. De los exámenes de laboratorios destacaron: SGOT 218 U/L, y SGPT 240 U/L, bilirrubinemia directa $12 \mathrm{mg} / \mathrm{dl}$, leucocitos $7.900 / \mathrm{mm}^{3}$, con $3 \%$ baciliformes, VHS $4 \mathrm{~mm} / \mathrm{h}$, y HBsAg positivo. El paciente fue tratado en una unidad de alta complejidad, pero pese al tratamiento y medidas de soporte falleció al noveno día de evolución.
Necropsia. Examen macroscópico: Destacaron ictericia acentuada; signos hemorragíparos de piel y mucosas; hidrotórax derecho de $300 \mathrm{ml}$; pulmones con áreas hemorrágicas y focos de consolidación; ascitis de $100 \mathrm{ml}$; hígado levemente disminuido de tamaño con arquitectura lobulillar borrosa y turbia; bazo, riñones y páncreas tumefactos. El corazón pesó $593 \mathrm{~g}$, globoso, con acentuado crecimiento de las cavidades izquierdas; ventrículo izquierdo con $14 \mathrm{~mm}$ de espesor y ventrículo derecho con $4 \mathrm{~mm}$ de espesor; endocardio parietal auricular y ventricular sin lesiones; en el borde libre del velo anterior de la válvula mitral se encontró

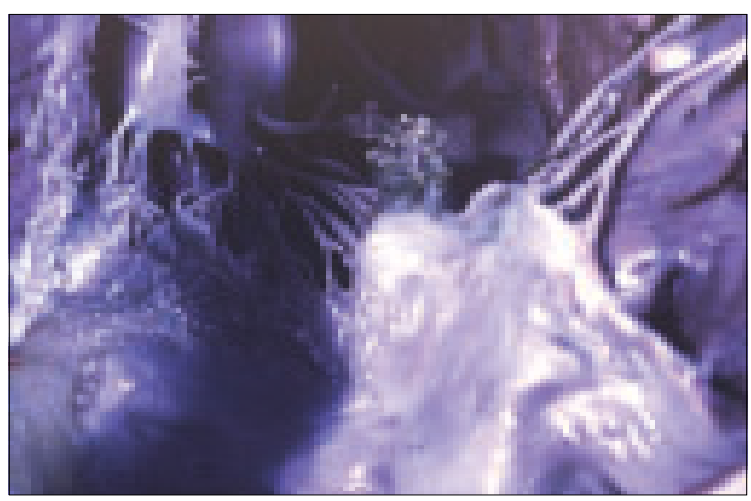

Figura 1. Examen macroscópico: válvula mitral con daño reumático crónico y en el velo anterior una gran vegetación trombótica. 
una gran vegetación, de base ancha, de $0,7 \times 0,5 \times 0,5$ $\mathrm{cm}$, de superficie irregular en parte papiliforme y granular, blanquecina-grisácea, dura y firmemente adherida (Figura 1), de la cual se envió muestra a cultivo aerobio y anaerobio, velos mitrales engrosados y cuerdas tendíneas fusionadas y engrosadas; válvula aórtica con fusión de comisuras, velos engrosados, deformados, rígidos, sin vegetaciones; válvulas tricúspide y pulmonar sin lesiones. Examen histopatológico: se encontró un miocardio de arquitectura conservada, con fibras hipertróficas, algunos trombos murales recientes y otros en organización avanzada; valvulopatía mitro-aórtica fibro-calcárea de tipo reumático con infiltración leucocitaria; vegetación mitral con gránulos bacterianos, con presencia de estructuras bacilares filamentosas, dispuestas en parte, de manera radiada y en parte desordenadas, grampositivas, fuertemente teñidas con Gomori - Grocott, (Figuras 2, 3, 4 y 5), y negativas con las tinciones de Fite-Faraco, Kinyoun y Ziehl-Neelsen.

Se concluyeron los diagnósticos anátomo-patológicos de hipertrofia cardíaca global de predominio izquierdo con una valvulopatía mitro-aórtica crónica de tipo reumático y trombo-endocarditis bacteriana subaguda con bacterias del tipo Actinomyces de la válvula mitral. El cultivo anaerobio de la vegetación fue informado positivo para Actinomyces sp. Otros diagnósticos fueron: bronconeumonía lobulillar confluente bilateral, atrofia amarilla del hígado y signos compatibles con hepatitis $\mathrm{B}$, pancreatitis y esplenitis de tipo séptico, tumefacción turbia de hígado y riñones, e induración rojo morena pulmonar.

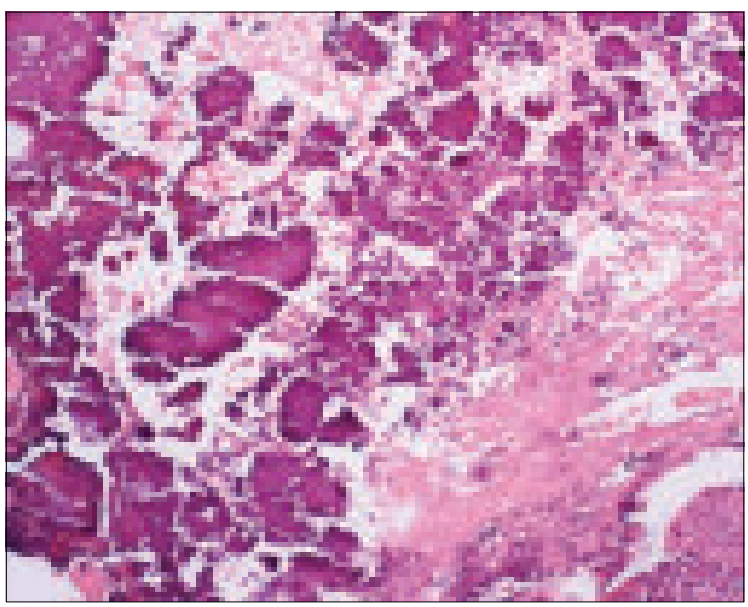

Figura 2. Examen microscópico: vegetación trombótica con gránulos bacterianos actinomicóticos (hematoxilina \& eosina, X 20, aumento original).

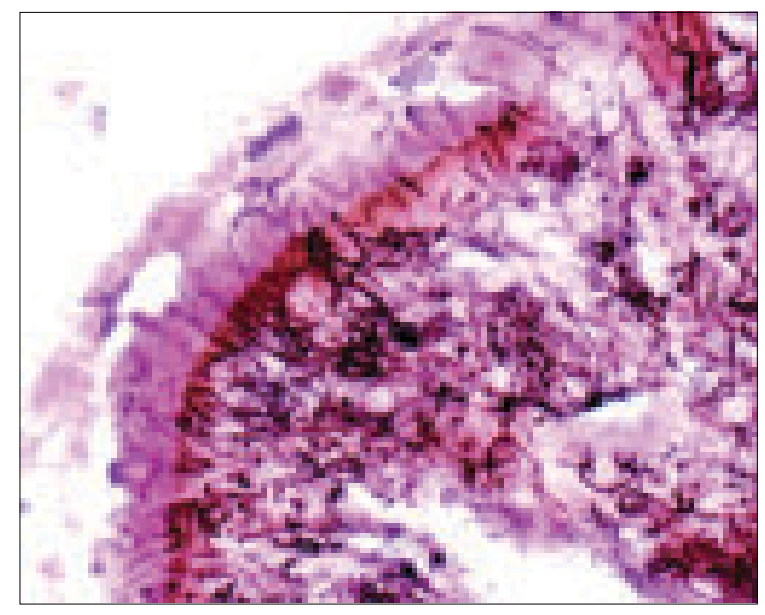

Figura 3. Examen microscópico: vegetación trombótica con gránulos bacterianos actinomicóticos con bacilos filamentosos dispuestos en forma radiada (Gomori Grocott, X 1.250, aumento original).



Figura 4. Examen microscópico: vegetación trombótica con gránulos bacterianos actinomicóticos con bacilos filamentosos dispuestos en forma desordenada (GomoriGrocott, X 1.250, aumento original).

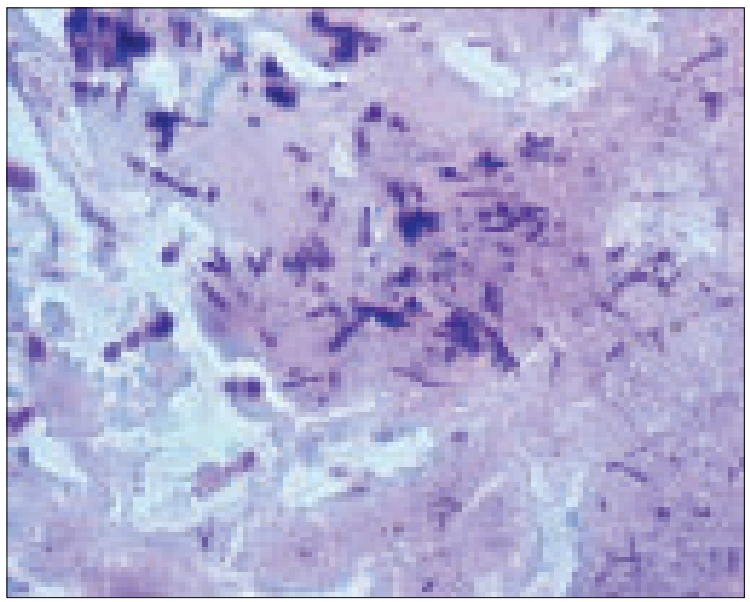

Figura 5. Examen microscópico: vegetación trombótica con gránulos bacterianos actinomicóticos con bacilos filamentosos grampositivos (Gram, X 1.250, aumento original). 


\section{Discusión}

La endocarditis actinomicótica es una condición muy inusual, difícil de plantear en el ejercicio clínico. En otros sitios, en especial las mucosas, la asociación de Actinomycetes sp y otras bacterias patógenas es usual $\mathrm{y}$, aunque es posible una co-infección endocárdica, desconocemos información al respecto.

La actinomicosis es una de las pocas enfermedades infecciosas bacterianas que pueden ser diagnosticadas a través de los hallazgos anátomo-patológicos, aún en ausencia de cultivos positivos ${ }^{5,6}$. Corresponde a cuadros crónicos supurativos de amplia distribución mundial, que usualmente afectan tejidos cérvico-faciales, torácicos, abdominales y raramente diseminados. Las especies patógenas más frecuentes en el hombre son Actinomyces israelii y Actinomyces bovis, saprófitos comunes de la mucosa de boca y amígdalas, entre otros sitios.

Otras especies como A. naeslundi, A. eriksoni, A. propionicus y $A$. viscosus ${ }^{3,4,6-8}$ han sido aisladas de lesiones actinomicóticas humanas; sin embargo, su frecuencia es baja y no pueden ser diferenciadas histopatológicamente de $A$. israelii ${ }^{5,6}$.

En la era pre-antibiótica, la actinomicosis fue una enfermedad importante y frecuentemente fatal. Hoy sin embargo, el diagnóstico es planteado rara vez, probablemente debido a que el tratamiento con antimicrobianos de amplio espectro puede controlar muchas infecciones antes que el diagnóstico específico sea formulado.

La mayoría de los casos de actinomicosis cardíaca descritos son secundarios a otro foco ${ }^{8-15}$, frecuentemente éste es bucal, correspondiendo a una períodontitis o abscesos radiculares ${ }^{16}$, o a focos pulmonares. El miocardio es el sitio de compromiso más frecuente; sólo en raras ocasiones hay extensión al pericardio y endocardio ${ }^{17-23}$. En algunas ocasiones, focos cutáneos, particularmente del área precordial, invaden el mediastino, siendo el pericardio el primero en afectarse, con obliteración del espacio pericárdico, posteriormente hay compromiso miocárdico y no es raro que el proceso se extienda al endocardio, perforando la pared. Signos clínicos de compromiso pericárdico se presentan $\sim 50 \%$ de los pacientes, manifestándose como insuficiencia cardíaca congestiva en la mayoría de los casos 5 . En Chile, a pesar de la extensa experiencia publicada sobre EI, aparentemente no se han comunicado casos asociados a bacterias del género Actinomyces ${ }^{24-27}$. Por otra parte, los casos y pe- queñas series de actinomicosis nativa que registra la literatura médica se restringen al ámbito ginecológico, abdomen, territorio tóraco-pulmonar, y región cérvicofacial, sin supuestos casos cardíacos s,28-34. $^{5}$.

En los casos de compromiso primario del endocar$\mathrm{dio}^{1-4}$, las manifestaciones clínicas son las de una EI sin características especiales ${ }^{1-4}$; sólo se puede plantear el diagnóstico, al tenerlo presente en casos sin respuesta a la antibioterapia habitual y ante el eventual aislamiento de las bacterias en los hemocultivos u observación directa, o cultivo de las biopsias del tejido afectado.

El diagnóstico definitivo de endocarditis actinomicótica se puede basar en el hallazgo aislado o combinado de la típica apariencia histopatológica de las vegetaciones o tejido cardíaco infectado o en el cultivo de las vegetaciones, material trombo-embólico o tejido cardíaco inflamado ${ }^{3}$. El diagnóstico morfológico de actinomicosis se sustenta en la identificación de gránulos con grupos de bacilos grampositivos ramificados; sin embargo, debe existir un alto grado de sospecha, ya que estos gránulos son escasos y las bacterias del género Actinomyces son difíciles de cultivar. En las biopsias, los filamentos se tiñen bien con Gomori-Grocott y Gram; no son ácido-alcohol resistente como algunas especies de Nocardia ${ }^{5,6}$. El centro de los gránulos puede contener estructuras semejantes a cocáceas grampositivas y bacilos gramnegativos, elementos que probablemente correspondan a remanentes de filamentos degenerados o, raramente, bacterias asociadas. La presencia de gránulos actinomicóticos y la ausencia de filamentos aislados en el exudado purulento ayuda a diferenciar la actinomicosis de la nocardiosis ${ }^{5,6}$.

Este caso ilustra una enfermedad rara, que fue diagnosticada gracias a la necropsia y la aplicación de un método de estudio, tinciones especiales y cultivo, que permitieron hacer el diagnóstico de EI actinomicótica de la válvula mitral.

\section{Resumen}

La infección actinomicótica del corazón es una enfermedad poco común, especialmente cuando el compromiso endocárdico valvular es primario. Sólo unos pocos casos han sido publicados. Comunicamos un caso de endocarditis primaria por Actinomyces sp de la válvula mitral, diagnosticada en la necropsia de un hombre de 34 años con antecedentes de valvulopatía reumática crónica, que falleció con una endocarditis infecciosa. 


\section{Referencias}

1.- Gutschik E. Endocarditis caused by Actinomyces viscosus. Case report. Scand J Infect Dis 1976; 8: 271-4.

2.- Lam S, Samraj J, Rahman S, Hilton E. Primary actinomycotic endocarditis; case report and review. Clin Infect Dis 1993; 16: 481-5.

3.- Mardis J S, Many W J Jr. Endocarditis due to Actinomyces viscosus. South Med J 2001; 94: 240-3.

4.- Julian K G, de Flesco L, Clarke L E, Parent L J. Actinomyces viscosus endocarditis requiring valve replacement. J Infect 2005; 50: 359-62.

5.- Oddó D, González S. Actinomycosis and Nocardiosis: a morphologic study of 17 cases. Pathol Res Pract 1986; 181: 320-6.

6.- Robboy S J, Vickery A L Jr. Tinctorial and morphologic properties distinguishing actinomycosis and nocardiosis. N Engl J Med 1970; 282: 593-6.

7.- Brown J R. Human actinomycosis. A study of 181 subjects. Human Pathol 1973; 4: 319-30.

8.- Binford C H, Dooley J. Diseases caused by fungi and actinomycetes. En Binford $\mathrm{CH}$ and Connord D (eds). Pathology of Tropical and Extraordinary Diseases. Washington DC. Armed Forces Institute of Pathology, 1976, pp 551-601.

9.- $\quad$ Lee C H, Lin M C, Tsai Y H, Tsao T C, Lan R S, Chinag I C. Thoracic actinomycosis. Review of 9 cases. Changgeng Yi Xue Za Zhi 1991; 14: 246-52.

10.- Hsieh M J, Liu H P, Chang J P, Chang C H. Thoracic actinomycosis. Chest 1993; 104: 366-70.

11.- Duhra P, Ilchyshyn A, Bell R. Thoracic actinomycosis. J R Soc Med 1992; 85: 44.

12.- Ibáñez Nolla J, Carratala J, Cucurull J,
Corbella X, Oliveras A, Curul V, et al. Actinomicosis torácica. Enferm Infecc Microbiol Clin 1993; 11: 433-6.

13.- Bentley E R, Ostransky D. Unusual manifestations of thoracic actinomycosis. J Am Osteopath Assoc 1994; 94: 249-53.

14.- Schwitter J, Rohner P, Makek M, Lareida J, Wust J, Greminger P, et al. Actinomycosisclinical and therapeutic considerations based in two personals case reports. Schweiz Med Wochenschr 1991; 121: 1319-27.

15.- Gebhardt U, Rost D. Thoracopulmonary actinomycosis. An unusual disease. Zentralbl Chir 1990; 115: 1579-82.

16. - Miller M, Haddad A J. Cervicofacial actinomycosis. Oral Surg Oral Med Oral Pathol Oral Radiol Endod 1998 May; 85: 496-508

17. - Nahass R G, Scholz P, Mackenzie J W, Gocke D J. Chronic constrictive pericarditis. A case report and review of the literature. Arch Intern Med 1989; 149: 1202-3.

18.- Slutzker A D, Claypool W D. Pericardial actinomycosis with cardial tamponade from contiguous throracic lesion. Thorax 1989; 44: $442-3$

19.- Orloff J J, Fine M J, Rihs J D. Acute cardiac tamponade due to cardiac actinomycosis. Chest 1988; 93: 661-3.

20.- Makaryus A N, Latzman J, Yang R, Rosman D. A rare case of Actinomyces israelii presenting as pericarditis in a 75year-old man. Cardiol Rev 2005; 13: 125-7.

21.- Janoskuti L, Lengyel M, Fenyvesi T. Cardiac actinomycosis in a patient presenting with acute cardiac tamponade and a mass mimicking pericardial tumor. Heart 2004; 90: e27.

22.- Esposti D, Lippolis A, Cipolla M, Bonazzi M. An uncommon cause of pericardial actinomycosis. Ital Heart J 2000; 1: $632-5$.

23.- Fife T D, Finegold S M, Grennan T. Pericardial actinomycosis: case report and review. Rev Infec Dis 1991; 13: 120-6.

24.- Oyonarte M, Montagna R, Braun S, Maiers E, Rojo P, Cumsille J F. Endocarditis infecciosa. Morbi-mortalidad en Chile. Resultado del estudio cooperativo nacional de endocarditis infecciosa (1998-2002). Rev Méd Chile 2003; 131: 237-50.

25.- Oyonarte M, Rojo P, Estévez A, Solís I, Akel C, Klenner C, et al. Endocarditis infecciosa: factores pronósticos de mortalidad en 131 casos. Rev Méd Chile 1997; 125: 165-73.

26.- Braun S, Escalona A, Chamorro G, Corbalán R, Pérez C, Labarca $\mathrm{J}$, et al. Endocarditis infecciosa: análisis de 261 casos $\mathrm{y}$ resultados del tratamiento con un enfoque multidisciplinario. Rev Méd Chile 2000; 128: 708-20.

27.- Braun S. Aspectos clínicos, diagnósticos bacteriológicos y ecocardiográficos. Rev Chilena de Cardiol 1898: 8: 203-9.

28.- Wells W, Campodónico I, Gunther A, Ried A. Actinomicosis del tracto genital femenino. Rev Chil Obstet Ginecol 1980; 45: 141-6.

29.- Mayerson D, Arteche G, Barria C, Wild R. Actinomicosis pélvica. Boletín Escuela Medicina UC (Chile) 1982; 27: 23-8.

30.- Carvajal C, Perales L, Otaiza F, Claure H, Fernández F, Palomo H. Actinomicosis del hígado. Rev Méd Chile 1987; 104: 818-20.

31.- Martínez J, Guzmán S, Oddó D. Actinomicosis abdominal. Revisión a propósito de tres casos. Rev Méd Chile 1989; 117: 1023-8.

32.- Wolff M, Levy J, Ballesteros J, Northland R. Actinomicosis: experiencia con 8 casos representativos del espectro clínico. Rev Méd Chile 1988; 116: 117-24.

33.- Bannura G. Actinomicosis abdominal. Rev Méd Chile 1994; 122: 1307-15.

34. - Ferrada C, Oddó D, Actinomicosis asociada a tumores malignos cérvico-faciales. Rev Chil Infect 1988; 5: 41-3. 